\title{
LncRNA-CASC7 inhibits the proliferation and migration of colon cancer by negatively regulating the PI3K/Akt signaling pathway
}

\author{
Bo Hao $^{1 "}$, Hexin Wen ${ }^{1 \#}$, Yingying Sun ${ }^{2}$, Zhenghong Le ${ }^{1}$, Zongbing Zhang ${ }^{1}$, Mulin Liu ${ }^{1}$, Ting Hu ${ }^{3}$ \\ ${ }^{1}$ Department of Gastrointestinal Surgery, The First Affiliated Hospital of Bengbu Medical College, Bengbu, China; ${ }^{2}$ Department of Pathology, The \\ First Affiliated Hospital of Bengbu Medical College, Bengbu, China; ${ }^{3}$ Department of Medical Oncology, The First Affiliated Hospital of Bengbu \\ Medical College, Bengbu, China. \\ Contributions: (I) Conception and design: B Hao, H Wen; (II) Administrative support: None; (III) Provision of study materials or patients: Z Le, M \\ Liu; (IV) Collection and assembly of data: Y Sun; (V) Data analysis and interpretation: Z Zhang, T Hu; (VI) Manuscript writing: All authors; (VII) \\ Final approval of manuscript: All authors. \\ "These authors contributed equally to this work. \\ Correspondence to: Ting Hu. Department of Medical Oncology, The First Affiliated Hospital of Bengbu Medical College, Bengbu 233004, China. \\ Email: hutingbbmu@163.com; Mulin Liu. Department of Gastrointestinal Surgery, The First Affiliated Hospital of Bengbu Medical College, Bengbu \\ 233004, China. Email: liumulin66@aliyun.com.
}

Background: This study aims to investigate the effect of LncRNA-CASC7 (cancer susceptibility candidate 7) on the proliferation and migration of colon cancer cells and its possible mechanism.

Methods: In this study, quantitative real-time polymerase chain reaction (qRT-PCR) was employed for the detection of lncRNA-CASC7 expression in 54 colon cancer tissues and 5 colon cancer cell lines. This study aimed to evaluate the significant correlation between the IncRNA-CASC7 expression, the clinical features, and the survival rate of patients. LncRNA-CASC7 was overexpressed by lipofectin transfection. Cell proliferation was detected by the methyl thiazolyl tetrazolium (MTT) assay. Transwell assay was conducted to examine cell migration and invasion. The target gene was verified by dual fluorescein. The expression of proliferation and invasion-related proteins was detected via western blotting (WB).

Results: The LncRNA-CASC7 expression in colon cancer was considerably decreased than in nearby healthy tissues $(\mathrm{P}<0.01)$. Its expression level was linked to survival rate, lymph node metastasis, and tumor node metastasis (TNM) stage. Similarly, the expression of lncRNA-CASC7 was decreased in 5 colon cancer cell lines. The proliferative, invasive, and migratory potential of cells was considerably decreased by lncRNACASC7 overexpression. Overexpression of lncRNA-CASC7 significantly inhibited the expression of proteins Ki-67 and PNCA (associated with proliferation) and proteins N-cadherin, E-cadherin, and vimentin (linked with metastasis). Further studies showed that overexpression of LncRNA-CASC7 could significantly inhibit the PI3K/Akt signaling pathway in colon cancer cells.

Conclusions: The PI3K/Akt signaling cascade is negatively regulated by LncRNA-CASC7, which serves as a tumor suppressor gene by attenuating colon cancer cell proliferation, invasion, and migration, thus affecting the tumor progression and prognosis of colon cancer patients.

Keywords: LncRNA-CASC7; colon cancer; proliferation; migration

Submitted Aug 31, 2021. Accepted for publication Oct 21, 2021.

doi: 10.21037/jgo-21-643

View this article at: https://dx.doi.org/10.21037/jgo-21-643

(c) Journal of Gastrointestinal Oncology. All rights reserved. 


\section{Introduction}

Colon cancer is a common malignant digestive tract tumor. Its morbidity and mortality rank among the highest of all tumors worldwide, and have shown an increasing trend in most countries (1). For patients with early colon cancer, the 5-year survival rate is high after surgical treatment. However, due to the relatively difficult early diagnosis of colon cancer and the lack of non-invasive detection methods, most patients with colon cancer are in the advanced stage when they are diagnosed, with metastasis or postoperative recurrence, resulting in the poor overall prognosis of patients suffering from colon cancer $(2,3)$. Therefore, extensive studies on the molecular mechanisms of the occurrence and expansion of colon cancer and finding new diagnostic and therapeutic markers are of great significance to improve the survival and quality of life of patients with colon cancer.

Long noncoding RNAs (lncRNAs) transcribed from the cell genome contain over 200 nucleotides without the ability to code for proteins (4). According to several reported studies, lncRNAs can serve as a novel regulator of cell proliferation, the cell cycle, differentiation, and apoptosis (5). Some studies have shown that there are also a large number of abnormally expressed lncRNAs in colon cancer tissues. These IncRNAs can promote or inhibit the incidence and development of colon cancer and are expected to become biomarkers for the early diagnosis of colorectal cancer (6-8). For example, by detecting the expression levels of lncRNAs in peripheral blood, it has been found that lncRNA SNHG11 may be a new therapeutic target for the treatment of colorectal cancer and a potential biomarker for the early detection of colorectal cancer (6). In addition, studies have shown that LINC00504 reprograms the central metabolism of colon cancer cells by regulating the expression of c-Myc, an important transcription regulator in colon cancer cells. This indicates that LINC00504 may become a potential target for therapeutic intervention (9). Therefore, identifying the differentially expressed lncRNAs in colon cancer tissues and exploring their biological functions will help to clarify the molecular regulation mechanism of colon cancer occurrence and development at the level of noncoding RNA. It may also provide new targets and a theoretical basis for early diagnosis, targeted therapy, personalized diagnosis, and curative effect evaluation of colon cancer.

LncRNA-CASC7 (cancer susceptibility candidate 7) is a noncoding RNA with a length of $9.3 \mathrm{~kb}$ (10). Current studies have shown that IncRNA CASC7 can significantly inhibit the occurrence and development of glioma, neuroblastoma, and colon cancer (11-13). However, the specific molecular mechanism by which lncRNA CASC7 regulates tumorigenesis and development remains unclear. Therefore, this study first identified the low expression of lncRNA-CASC7 has the potential to influence the progression and prognosis of colon cancer. Furthermore, it was found that lncRNA-CASC7 can inhibit the proliferation, migration, and invasion of colon cancer cells by negatively regulating the PI3K/Akt signaling cascade, and hence influences tumor development and patient prognosis. The present results suggested that inhibition of dual target such as PI3K (inhibitor) or lncRNA-CASC7 (activator) as a potentially good option for developing a novel targeted therapy for colon cancer. We present the following article in accordance with the MDAR reporting checklist (available at https://dx.doi.org/10.21037/jgo-21-643).

\section{Methods}

\section{General data}

A total of 54 patients with colon cancer treated in our hospital were enrolled in the study. Tumor tissues and surrounding healthy tissues (distance from tumor edge $\geq 5 \mathrm{~cm}$ ) were collected. The obtained tissue samples were instantly frozen, using liquid nitrogen. The average age of the patients was $51.5 \pm 6.2$ years. There were 30 male patients and 24 female patients. No chemotherapy or radiotherapy was performed before the operation in all patients, and the disease was confirmed by pathology. The approval for the current study was provided by of The First Affiliated Hospital of Bengbu Medical College (No. 2020238). Before starting the experimental study, all participants and their families were made aware of the study and submitted signed informed consent. There were no deviations from the Declaration of Helsinki in any of the study's methods involving human subjects.

\section{Cell lines}

Five colon cancer cell lines (SW480, SW620, Caco-2, HCT-116, and HT-29) and the normal colon epithelial cell line FHC were purchased from ATCC, USA. All cell lines were grown in RPMI enriched with FBS (10\%) and antibiotics (i.e., penicillin and streptomycin). At $37^{\circ} \mathrm{C}$ the culture mixture was placed in a cell incubator maintained with a $5 \% \mathrm{CO}_{2}$ supply. 


\section{LncRNA-CASC7 expression detected by qRT-PCR}

The total RNA was extracted from both cell lines and tissue samples by using the total RNA extraction kit, followed by synthesizing cDNA from total RNA $(5 \mu \mathrm{g})$ using the reverse transcription. Then, RT-PCR was carried out by the SYBR Green method. The reaction conditions were as follows: pre-denaturation at $95{ }^{\circ} \mathrm{C}$ for $10 \mathrm{~min}$; then 40 cycles of $95{ }^{\circ} \mathrm{C}$ for $10 \mathrm{~s}, 60{ }^{\circ} \mathrm{C}$ for $30 \mathrm{~s}$, and $72{ }^{\circ} \mathrm{C}$ for $30 \mathrm{~s}$. The reaction system was added in strict accordance with the instructions. GAPDH was used as an internal reference. The relative expression of 1ncRNA-CASC7 was calculated by the $2^{-\Delta \Delta \mathrm{Ct}}$ method: $\Delta \mathrm{Ct}=\mathrm{Ct}_{\mathrm{lncRNA}-\mathrm{CASC} 7}-$ $\mathrm{Ct}_{\mathrm{GAPDH}}$. The primer sequence of lncRNA-CASC7 was forward: 5'-ACATGACCTATGCCGGGAGGC-3'; reverse: 5'-CTCAAGCCGAAGTAACGTGGA-3'. The sequence of the GAPDH primer was determined with reference to a previous study (14).

\section{Lipofectin transfection}

By constructing and subcloning the overexpressed lncRNACASC7 vector into transfection plasmids, we have generated an improved version of the pcDNA3.1-CASC7 viral vector with reference to a previously reported study (15). SW480 and HCT116 cells were inoculated into 6 -well plates at a density of $2 \times 10^{5}$ cells per well and cultured in a cell incubator overnight. When the cells adhered to the walls and grew to a fusion degree of about $70 \%$, the IncRNA-CASC7 overexpression vector and blank control were transfected according to the operation instructions of Lipofectamine 2000. The transfection efficiency was verified by qRT-PCR.

\section{Cell proliferation detection by the MTT assay}

The cells $\left(2.5 \times 10^{4}\right.$ cells/well $)$ in each group were inoculated into 96-well plates, and cultured in a cell incubator for $48 \mathrm{~h}$ to adhere to the walls, followed by adding $20 \mu \mathrm{L}$ of MTT reagent $(5 \mathrm{~g} / \mathrm{L})$ to each well. The cells were grown for another $4 \mathrm{~h}$, then added with $150 \mu \mathrm{L}$ dimethyl sulfoxide, followed by gentle shaking and mixing. Then, the $\mathrm{OD}_{490 \mathrm{~nm}}$ of cells in each group at $0,24,48,72$, and $96 \mathrm{~h}$ was detected.

\section{Colony formation}

The cells in good growth condition were harvested and inoculated into 6 -well plates at a density of $1 \times 10^{3}$ cells per well, gently shaken to be evenly dispersed. Next, the incubation of the underlined cells was carried out at $\mathrm{CO}_{2}$ $(5 \%)$ and $37^{\circ} \mathrm{C}$. When there was a visible cell colony, the culture (about 14 days) was stopped. For cell fixing (15 min), paraformaldehyde (4\%) was used, and then added crystal violet dye (1\%) and stained for $10 \mathrm{~min}$. The excess dye was washed away with PBS buffer, and photos were taken after drying at room temperature for counting and analysis. The number of cell masses $\geq 50$ cells was taken as the number of colonies.

\section{The migratory and invasive potential of the cell evaluated by the Transwell assay}

For the cell migration experiment, the cells in each group were collected and made into single-cell suspensions, and the cell concentration was adjusted to $5 \times 10^{4}$ cells $/ \mathrm{mL}$. A $100 \mu \mathrm{L}$ cell suspension was added to the Transwell upper chamber, a $500 \mu \mathrm{L}$ RPMI medium comprising FBS (10\%) was added. Post-2-days of culture, the upper chamber cells were wiped with a cotton swab and fixed with paraformaldehyde (4\%) for $30 \mathrm{~min}$, followed by staining with crystal violet $(0.1 \%)$, and then observed and photographed under an inverted phase-contrast microscope $(\times 200)$. Five visual fields were randomly observed and counted. For the Transwell invasion experiment, the Matrigel glue (precooled at $4{ }^{\circ} \mathrm{C}$ in advance) was diluted with RPMI1640 medium at a ratio of 1:8 and evenly spread on the Transwell upper chamber, and kept sterile at $37{ }^{\circ} \mathrm{C}$ overnight and dried. The remaining steps were the same as the cell migration experiment.

\section{Western blotting (WB)}

The cells in each group were made into single-cell suspensions, and the total protein was extracted by RIPA cell lysis buffer containing protease inhibitor PMSF. The protein was detected quantitatively by the BCA method. Then, $30 \mu \mathrm{g}$ protein samples were used for sodium dodecyl sulfate polyacrylamide gel electrophoresis (SDS-PAGE), followed by transferring onto a PVDF membrane and sealed with $5 \%$ skim milk powder for $2 \mathrm{~h}$. Rat anti-human c-Myb primary antibody diluted at 1:800 was added and incubated overnight at $4{ }^{\circ} \mathrm{C}$, then horseradish peroxidaselabeled 1:500 diluted secondary antibody $\operatorname{IgG}$ was added, followed by incubation at $25^{\circ} \mathrm{C}$ for $2 \mathrm{~h}$. Post developing with the ECL chemiluminescence reagent, the membrane was put into the gel imaging system to take photos, and grayscale analysis was carried out with Image J software. 
A

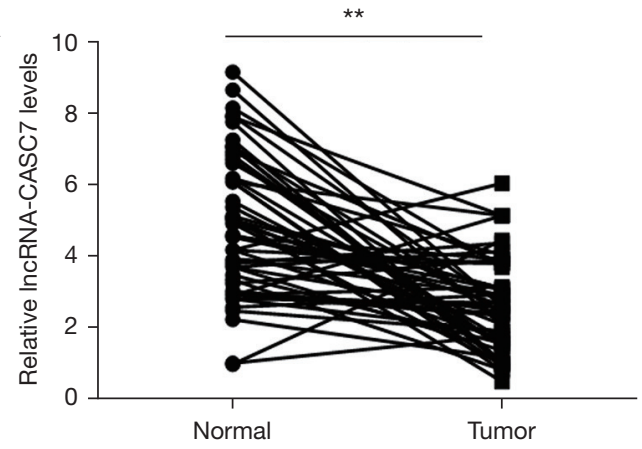

B

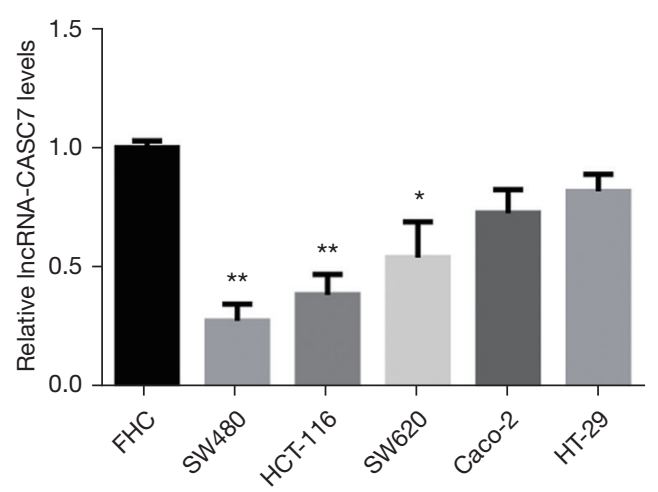

Figure 1 LncRNA-CASC7 expression in colon cancerous tissues and cell lines. (A) The relative expression level of lncRNA-CASC7 in clinical tissue samples; (B) expression level of lncRNA-CASC7 in each cell line. *, $\mathrm{P}<0.05$; **, $\mathrm{P}<0.01$.

\section{Statistical evaluations}

Statistical software (SPSS 22.0) was employed to analyze the obtained data. The obtained results were indicated as mean \pm standard deviation $(\mathrm{x} \pm \mathrm{s})$. An independent sample $t$-test and one-way ANOVA were conducted to compare two, and multiple groups, accordingly. $\mathrm{P}<0.05$ indicated that the differences between the groups were significant.

\section{Results}

\section{LncRNA-CASC7 expression in tissue samples and cell lines identified by qRT-PCR}

The relative expression level of lncRNA-CASC7 in 54 colon cancer tissues was considerably decreased in 54 colon cancerous tissues relative to the nearby healthy tissues $(\mathrm{P}<0.01$, Figure 1A). Similarly, as indicated in Figure $1 B$, the expression level of lncRNA-CASC7 was considerably lowered than the normal colon epithelial cell line FHC $(\mathrm{P}<0.05)$, demonstrating that lncRNA-CASC7 was downregulated in colon cancer.

\section{Correlation between the expression of IncRNA-CASC7 and the clinicopathological characteristics or survival rate of patients with colon cancer}

The correlation analysis between the IncRNA-CASC7 expression in tumor tissues and the clinicopathological parameters of patients showed that the expression of lncRNA-CASC7 in tumor tissues was considerably linked with TNM stage and the presence of lymph node metastasis (both $\mathrm{P}<0.05$ ), but not with gender, age, tumor size, degree of differentiation, and depth of invasion (all $\mathrm{P}>0.05$ ), as shown in Table 1. The Kaplan-Meier survival curve showed that colon cancer patients with elevated expression of lncRNA-CASC7 had longer overall survival (OS) and disease-free survival (DFS) (both $\mathrm{P}<0.05$ ), as shown in Figure 2. The results suggest that the expression of the lncRNACASC7 gene influences the rate of tumor growth and survival in patients with colon cancer.

\section{Impact of lncRNA-CASC7 expression on the proliferation of colon cancer cells}

To further study the impact of 1ncRNA-CASC7 on the biological function of colon cancer cells, the lncRNACASC7 overexpression vector (pcDNA-CASC7), blank control, empty vector group (pcDNA-control), and CASC7 overexpression group (pcDNA-CASC7) were constructed, then SW480 and HCT-116 cells were transfected. The transfection efficiency of each group was verified by qRTPCR. The data indicated transfection of the pcDNACASC7 vector significantly promoted the expression level of lncRNA-CASC7 in SW480 and HCT-116 cells (both $\mathrm{P}<0.01$ ), as shown in Figure $3 A, 3 B$, indicating that the transfection was successful.

Firstly, the impact of overexpression of lncRNA-CASC7 on the proliferation of colon cancer cells was detected by the MTT and colony formation assays. The results showed that after elevated expression of lncRNA-CASC7, the cell proliferation activity decreased significantly from $48 \mathrm{~h}$ $(\mathrm{P}<0.05)$, as shown in Figure $4 A$. The results of the plate colony formation experiment showed that the number of colony formations of cells in the overexpression lncRNACASC7 group was considerably decreased than that in the pcDNA-control group $(\mathrm{P}<0.05)$, as shown in Figure $4 B$. 
Table 1 Correlation between lncRNA-CASC7 expression and clinicopathological parameters

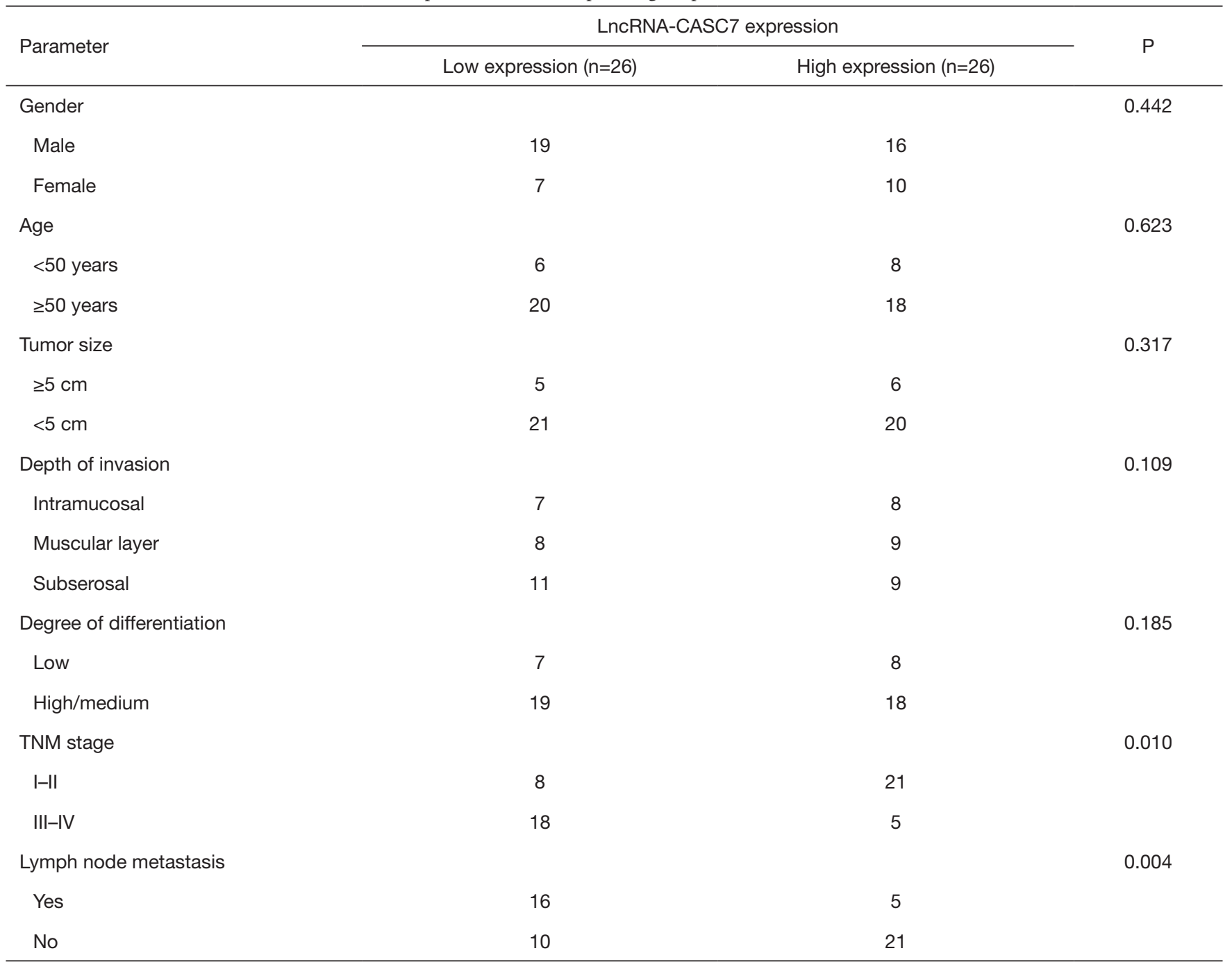
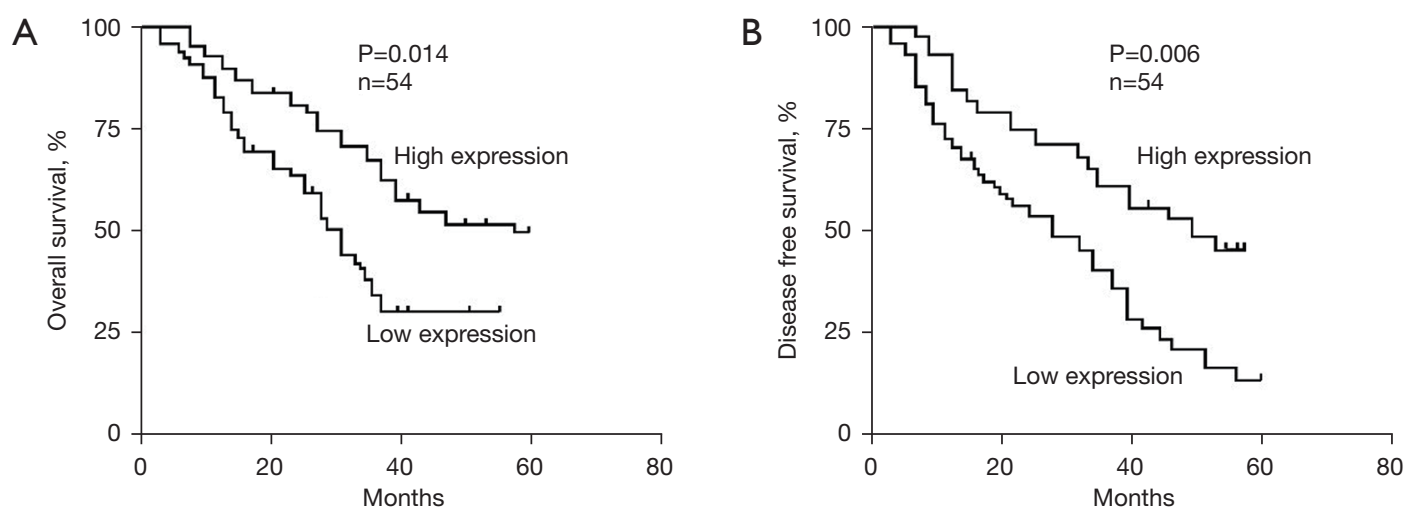

Figure 2 Effect of lncRNA-CASC7 expression on overall survival (OS) and disease-free survival (DFS) in patients. (A) Effect of lncRNACASC7 expression on OS in patients; (B) effect of lncRNA-CASC7 expression on DFS in patients. 

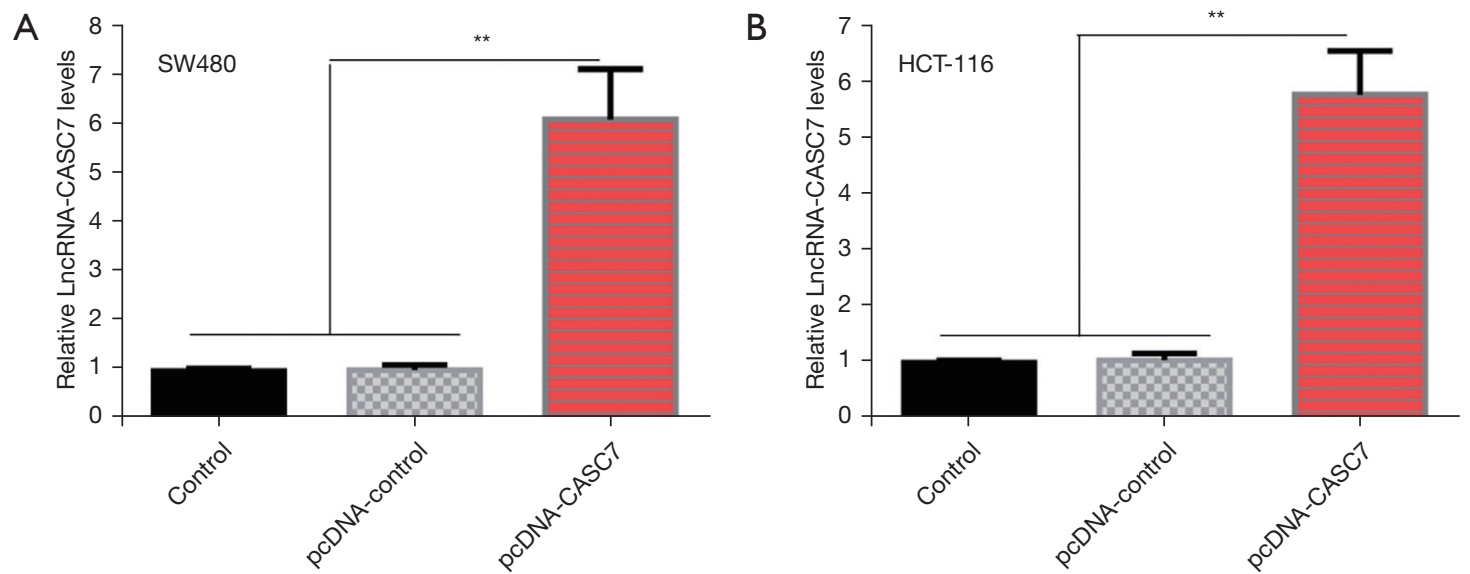

Figure 3 The effects of pcDNA-CASC7 transfection on the lncRNA-CASC7 expression in HCT-116 and SW480 cells by qRT-PCR. (A) Detection of the effect of pcDNA-CASC7 transfection on the lncRNA-CASC7 expression in SW480 cell; (B) detection of the impact of pcDNA-CASC7 transfection on the LncRNA-CASC7 expression in HCT-116 cell. **, $\mathrm{P}<0.01$.

These results indicated that lncRNA-CASC7 might suppress the growth of colon cancer cells.

\section{Detection of the migratory and invasive potential of SW480 and HCT-116 cells by the Transwell method}

In the transwell cell migration experiment, the number of cells that penetrated the membrane was considerably decreased in the overexpression 1ncRNA-CASC7 group than in the pcDNA-control group $(\mathrm{P}<0.05)$, while the number of cells that penetrated the membrane in the control group and the pcDNA-control group did not differ considerably $(\mathrm{P}>0.05)$, as indicated in Figure 5. This suggests that lncRNA-CASC7 has the potential to suppress colon cancer cell migration and invasion.

\section{LncRNA-CASC7 attenuates the proliferative and invasive potential of colon cancerous cells through the PI3K/Akt signaling cascade}

In the current study, the obtained data revealed that the elevated expression of IncRNACASC7 considerably attenuated the proliferative, invasive, and migratory potential in colon cancer. WB was carried out to validate the presence of proteins involved in cell proliferation, invasion, and migration. Relative to the blank control group, the empty vector (pcDNA-control) had no considerable impact on the expression of the proteins associated with the proliferative, invasive, and migratory potential of the colon cancer cells (SW480), while an elevated expression of
lncRNA-CASC7 could considerably enhance the expression of the cell adhesion protein E-cadherin, and inhibit the expression of the adhesion protein $\mathrm{N}$-cadherin and the cytoskeleton protein vimentin. In addition, overexpression of lncRNA-CASC7 could considerably suppress the expression of proteins Ki-67 and PCNA associated with cellular proliferation, as indicated in Figure 6. The proliferative and invasive potential of colorectal cancer is enhanced by an abnormally active PI3K-Akt signaling cascade that considerably contributes to the incidence and progression of cancer $(16,17)$. Therefore, to further explore the molecular signaling pathway by which lncRNACASC7 overexpression inhibits colon cancer, the expression changes in important proteins in the PI3K-Akt signaling cascade were further detected by Western blotting. In comparison to the blank control group, the empty vector (pcDNA-control) had no considerable impact on the expression of Akt, phosphorylated Akt (p-Akt), PI3K, and phosphorylated PI3K (p-pi3k) in colon cancer SW480 cells, while overexpression of lncRNA-CASC7 could significantly inhibit the expression of p-pi3k and p-Akt and had no considerable impact on the expression of total PI3K and total Akt, as indicated in Figure 7.

\section{Discussion}

The occurrence, development, invasion, and metastasis of colon cancer are complex and involve the expression imbalance of a variety of genes, but the specific mechanism is not clear. LncRNAs are transcribed from the cell genome. 
A

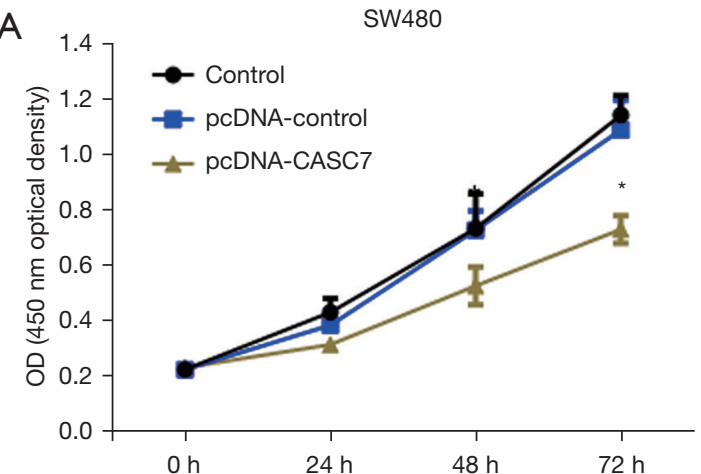

B
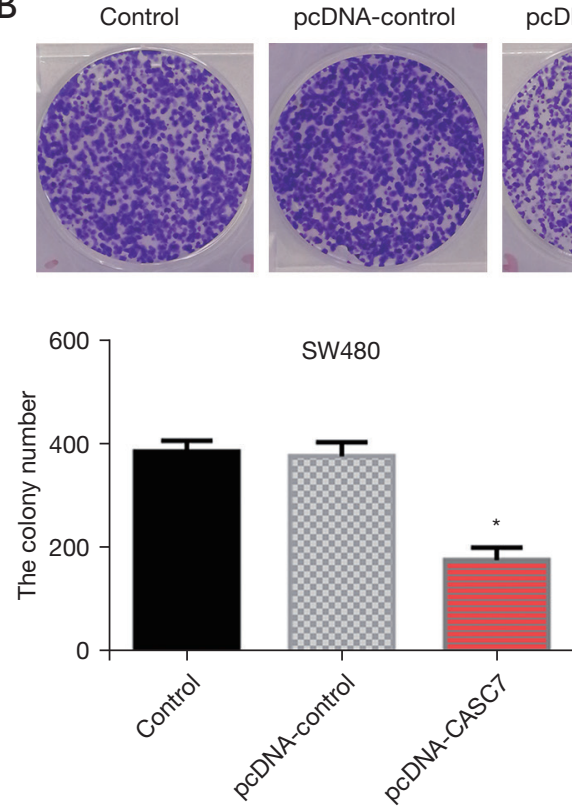

HCT-116
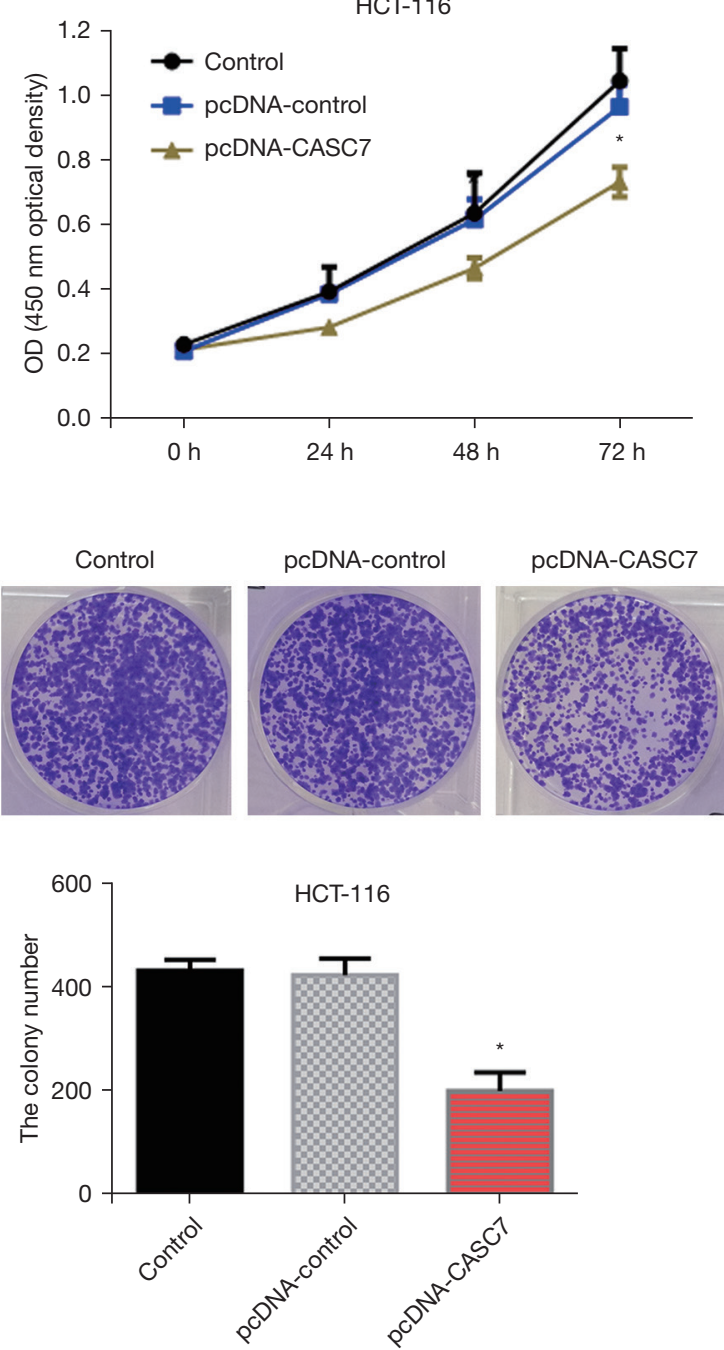

Figure 4 The effects of LncRNA-CASC7 elevated expression on the proliferative potential of the colon cancer cells, i.e., HCT-116 and SW480. (A) Detection of the effect of LncRNA-CASC7 expression on the proliferative potential of colon cancer cells SW480 and HCT-116 by the MTT assay; (B) detection of the impact of LncRNA-CASC7 expression on the colony-forming ability of colon cancerous cells HCT116 and SW480 by the plate colony formation assay. The cells fixation was carried out by paraformaldehyde (4\%) for $15 \mathrm{~min}$, then added crystal violet (1\%) and stained for $10 \mathrm{~min}$. Scale bars $=5 \mathrm{~mm},{ }^{*}, \mathrm{P}<0.05$.

They have no protein coding ability, but can widely participate in many important regulatory processes such as chromosome silencing, genome imprinting, chromatin modification, transcriptional activation, transcriptional interference, and intranuclear transport $(18,19)$. The expression of lncRNAs is conservative, tissue-specific, and sequential. Previous studies have shown that miRNAs contribute to several processes including cell growth, differentiation, and apoptosis $(5,20)$. With the deepening of the study of lncRNAs, more and more lncRNAs show potential as tumor-specific markers, and have good prospects in the clinical diagnosis, treatment, and prognosis of tumors.

LncRNA-CASC7 is a noncoding RNA found in recent years. It is abnormally expressed in a variety of diseases and plays an important physiological regulatory role (11,15,21-22). Gong et al. revealed that IncRNA-CASC7 expression has been decreased in glioma tissues and cell lines, which indicates the poor survival of glioma patients, while overexpression of CASC7 inhibits the proliferation of glioma cells and induces glioma cell apoptosis. In glioma cells, molecular mechanism research revealed a negative 

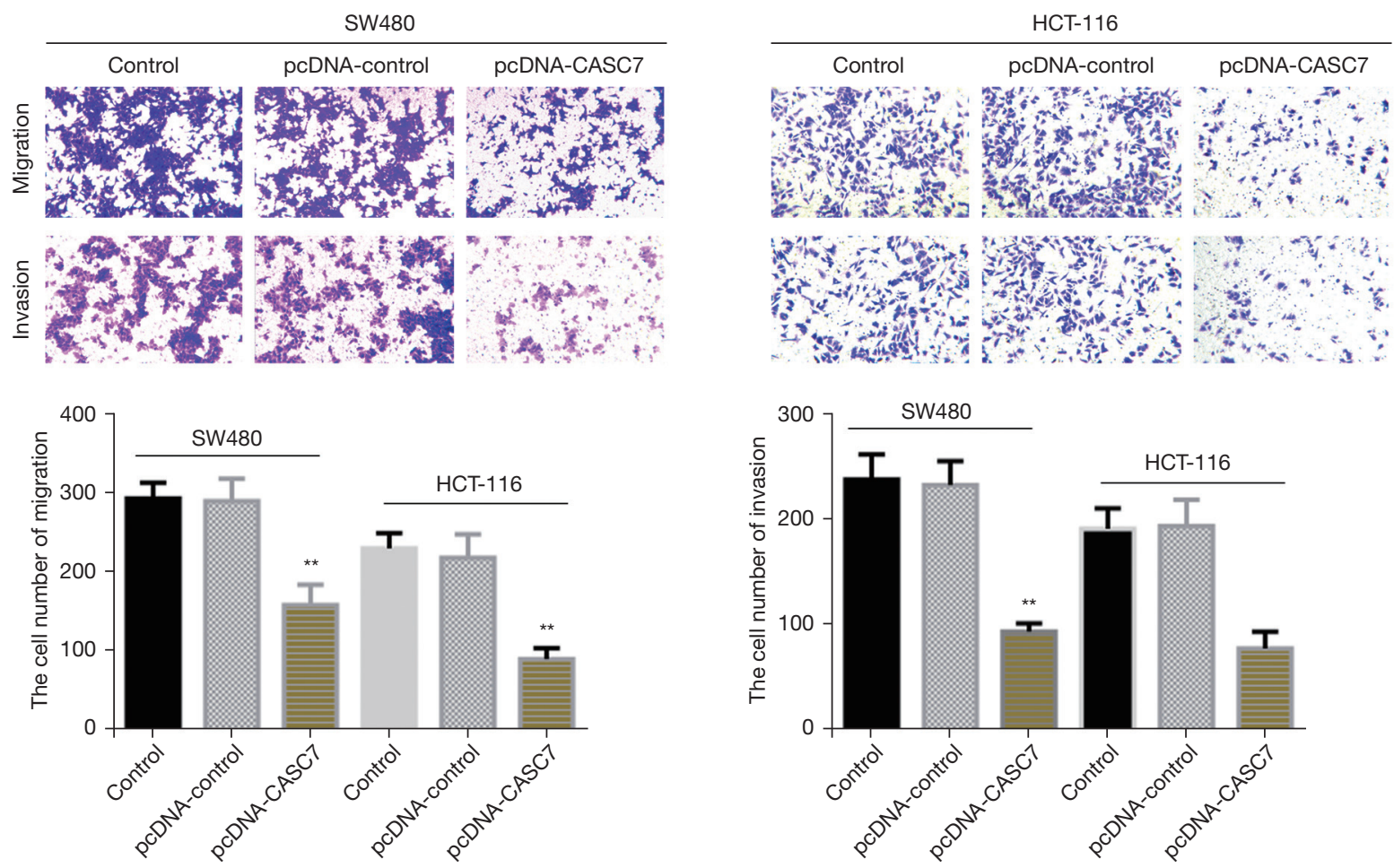

Figure 5 The effects of lncRNA-CASC7 overexpression on the migratory and invasive potential of colon cancer cells, i.e., HCT-116 and SW480 by the Transwell assay (crystal violet staining, $\times 100$ ). The cells fixation was carried out with paraformaldehyde (4\%) for 15 min, then crystal violet dye $(1 \%)$ was added and stained for $10 \mathrm{~min}$. Scale bars $=200 \mu \mathrm{m}$. **, $\mathrm{P}<0.01$.
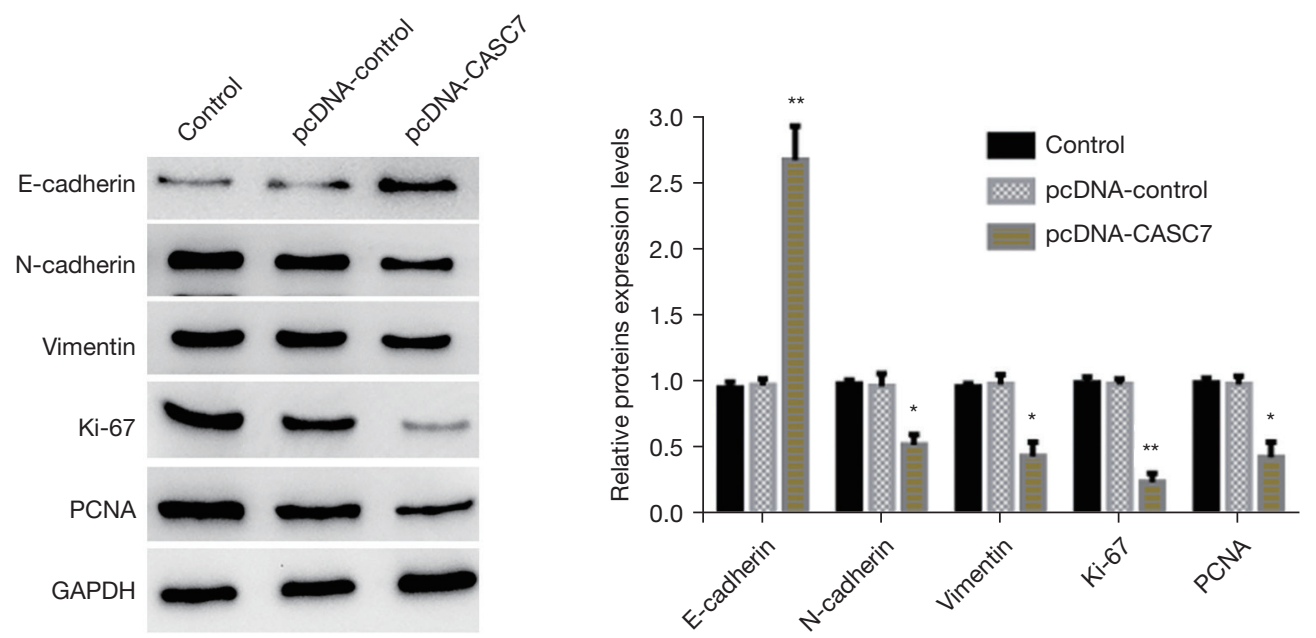

Figure 6 The impact of elevated expression of lncRNA-CASC7 on the expression of the protein (linked with proliferation and invasion) in the colon cancer cell line SW480 by Western blotting. *, $\mathrm{P}<0.05 ;{ }^{* *}, \mathrm{P}<0.01$.

association between lncRNA-CASC7 expression and the core factor of the Wnt/-catenin signaling cascade. It is speculated that lncRNA-CASC7 may inhibit the occurrence and development of glioma by regulating the $\mathrm{Wnt} / \beta$-catenin signaling cascade (11). Xu et al. found that lncRNACASC7 is involved in the regulation of heart failure by regulating the miR-30c expression (23). This study found that the IncRNA-CASC7 expression was considerably 

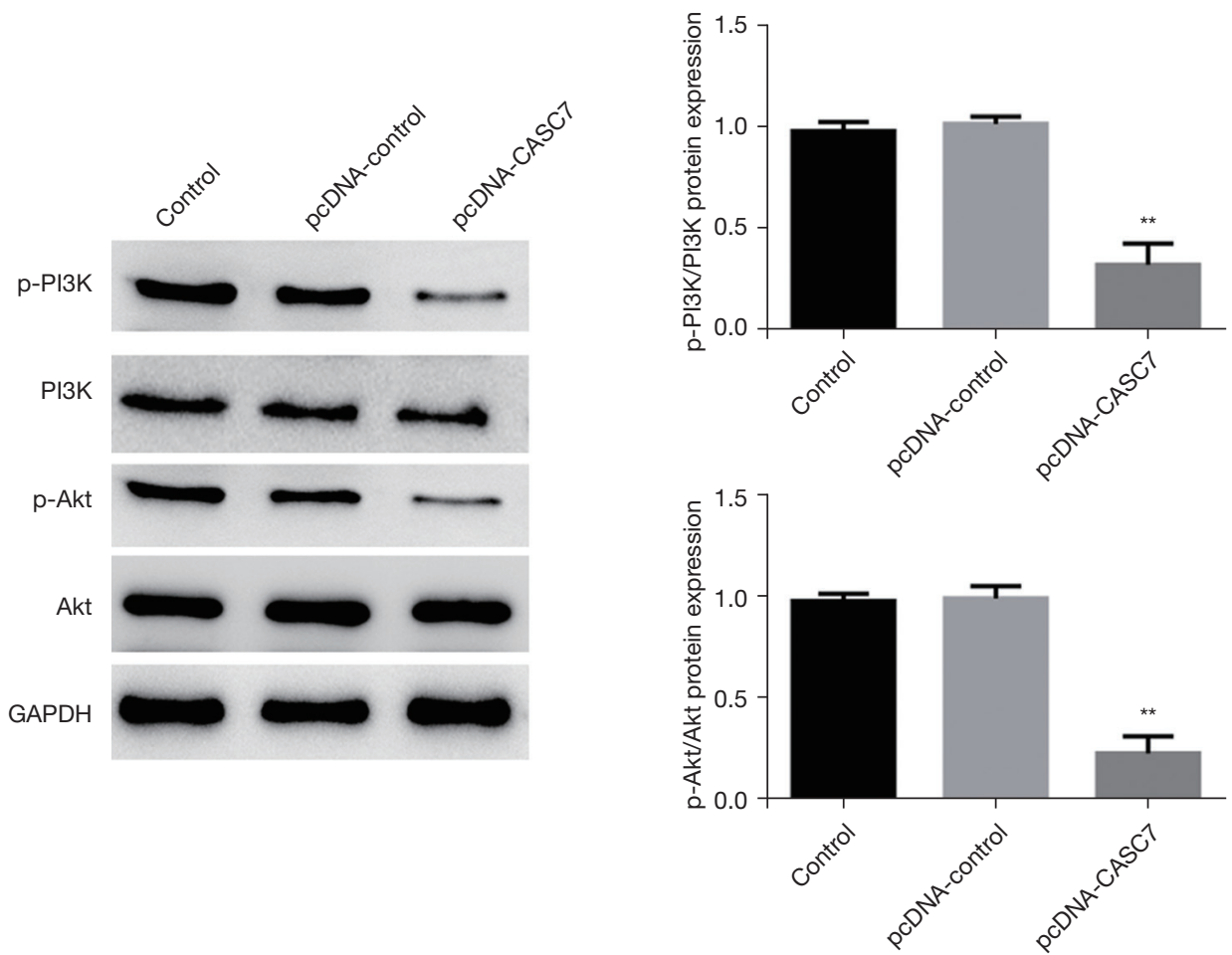

Figure 7 The impact of elevated expression of LncRNA-CASC7 on the proteins-expression (linked with PI3K-Akt signaling cascade) in the colon cancer cell line SW480 by Western blot. ${ }^{* *}, \mathrm{P}<0.01$.

decreased in colon cancer tissues and cell lines. In tumor tissues, lncRNA-CASC7 expression was considerably linked with the TNM stage and metastasis of the lymph node. Prognostic analysis showed that lncRNA-CASC7 was significantly correlated with OS and DFS in patients with colon cancer, that is, those with elevated expression of IncRNA-CASC7 showed better survival outcomes. After lncRNA-CASC7 was successfully overexpressed in colon cancer cell lines, i.e., HCT-116 and SW480, we observed that the proliferative, migratory, and invasive potential of cells was considerably lowered, indicating that lncRNACASC7 can attenuate the proliferative, migratory, and invasive potential of colon cancerous cells and perform similar functions to tumor suppressor genes. Further molecular mechanism experiments showed that elevated expression of lncRNA-CASC7 considerably enhanced the expression of the cell adhesion protein E-cadherin and inhibited the expression of the adhesion protein $\mathrm{N}$-cadherin and the cytoskeleton protein vimentin, and overexpression of lncRNA-CASC7 also significantly inhibited the expression of cell proliferation-related proteins, i.e., PCNA and $\mathrm{Ki}-67$ associated with cellular proliferation.

The PI3K/Akt signaling cascade is crucial to many aspects of colon cancer cell growth and survival, and it also regulates the acquisition of drug resistance and colon cancer metastasis (15). In addition, the PI3K/Akt pathway is a commonly dysregulated pathways and mediates multiple cellular functions critical to tumor progression, proliferation, invasion as well as poor clinical outcomes of the patients. A previous study has shown that some IncRNAs contribute to the occurrence and progression of tumors by regulating the PI3K/Akt signaling cascade (24). For example, lncRNA AK023391 enhances the occurrence and invasion of gastric cancer by stimulating the PI3K/Akt signaling cascade (25). However, in osteosarcoma, elevated expression of LINC00628 attenuates the proliferative, invasive, and migratory potential of osteosarcoma cells and promotes the apoptotic process by inactivating the PI3K/Akt signaling cascade (26). The data obtained from this study revealed that lncRNA-CASC7 overexpression significantly inhibits the expression of p-pi3k and p-Akt, but has no considerable impact on the expression of total PI3K and total Akt. However, it is still unclear how lncRNACASC7 inhibits PI3K/Akt signaling. In the follow-up study, we will focus on exploring whether lncRNA-CASC7 plays a role through miRNA. 
In conclusion, this study found that the expression of lncRNA-CASC7 was down-regulated in colon cancer, and elevated expression of 1ncRNA-CASC7 attenuated the proliferative, migratory, and invasive potential of colon cancer cells. Furthermore, this study indicated that the IncRNA-CASC7 gene has a function comparable to that of tumor suppressor genes and that the level of IncRNACASC7 expression in tumor tissues has a considerable impact on the tumors growth and the survival of colon cancer patients.

\section{Acknowledgments}

Funding: The current study was partially funded by Anhui Natural Science Foundation Project (2108085MH291), Scientific Research Project of Anhui Provincial Health and Family Planning Commission (2016QK016), Bengbu City Science and Technology Major Special Fund Project (BYLK201825), 512 Talent Cultivation Plan of Bengbu Medical College (by51201107), Research and Innovation Team of Bengbu Medical College (BYKC201909), Natural Science Foundation of Bengbu Medical College (2020byzd153).

\section{Footnote}

Reporting Checklist: The authors have completed the MDAR reporting checklist. Available at https://dx.doi. org/10.21037/jgo-21-643

Data Sharing Statement: Available at https://dx.doi. org/10.21037/jgo-21-643

Conflicts of Interest: All authors have completed the ICMJE uniform disclosure form (available at https://dx.doi. org/10.21037/jgo-21-643). The authors have no conflicts of interest to declare.

Ethical Statement: The authors are accountable for all aspects of the work in ensuring that questions related to the accuracy or integrity of any part of the work are appropriately investigated and resolved. This study was approved by the ethics committee of The First Affiliated Hospital of Bengbu Medical College (No. 2020238). All participants and their families were aware of the study, and all participants provided written informed consent before commencement of the study. All procedures performed in this study involving human participants were in accordance with the Declaration of Helsinki (as revised in 2013).

Open Access Statement: This is an Open Access article distributed in accordance with the Creative Commons Attribution-NonCommercial-NoDerivs 4.0 International License (CC BY-NC-ND 4.0), which permits the noncommercial replication and distribution of the article with the strict proviso that no changes or edits are made and the original work is properly cited (including links to both the formal publication through the relevant DOI and the license). See: https://creativecommons.org/licenses/by-nc-nd/4.0/.

\section{References}

1. Pawlik TM. Colon Cancer. Surg Oncol Clin N Am 2018;27:xiii-xiv.

2. Benson AB, Venook AP, Al-Hawary MM, et al. NCCN Guidelines Insights: Colon Cancer, Version 2.2018. J Natl Compr Canc Netw 2018;16:359-69.

3. Banerjee A, Pathak S, Subramanium VD, et al. Strategies for targeted drug delivery in treatment of colon cancer: current trends and future perspectives. Drug Discov Today 2017;22:1224-32.

4. Bhan A, Soleimani M, Mandal SS. Long Noncoding RNA and Cancer: A New Paradigm. Cancer Res 2017;77:3965-81.

5. Peng WX, Koirala P, Mo YY. LncRNA-mediated regulation of cell signaling in cancer. Oncogene 2017;36:5661-7.

6. Xu W, Zhou G, Wang H, et al. Circulating lncRNA SNHG11 as a novel biomarker for early diagnosis and prognosis of colorectal cancer. Int J Cancer 2020;146:2901-12.

7. Wang XJ, Zeng B, Lin S, et al. An Integrated miRNAlncRNA Signature Predicts the Survival of Stage II Colon Cancer. Ann Clin Lab Sci 2019;49:730-9.

8. Zhang Z, Qian W, Wang S, et al. Analysis of lncRNAAssociated ceRNA Network Reveals Potential lncRNA Biomarkers in Human Colon Adenocarcinoma. Cell Physiol Biochem 2018;49:1778-91.

9. Feng J, Ma J, Liu S, et al. A noncoding RNA LINC00504 interacts with c-Myc to regulate tumor metabolism in colon cancer. J Cell Biochem 2019;120:14725-34.

10. Lennox KA, Behlke MA. Cellular localization of long non-coding RNAs affects silencing by RNAi more than by antisense oligonucleotides. Nucleic Acids Res 2016;44:863-77.

11. Gong X, Liao X, Huang M. LncRNA CASC7 inhibits 
the progression of glioma via regulating $W n t / \beta$-catenin signaling pathway. Pathol Res Pract 2019;215:564-70.

12. Zhou X, Lu H, Li F, et al. LncRNA cancer susceptibility candidate (CASC7) upregulates phosphatase and tensin homolog by downregulating miR-10a to inhibit neuroblastoma cell proliferation. Neuroreport 2020;31:381-6.

13. Zhang Z, Fu C, Xu Q, et al. Long non-coding RNA CASC7 inhibits the proliferation and migration of colon cancer cells via inhibiting microRNA-21. Biomed Pharmacother 2017;95:1644-53.

14. Li W, Yu KN, Bao L, et al. Non-thermal plasma inhibits human cervical cancer HeLa cells invasiveness by suppressing the MAPK pathway and decreasing matrix metalloproteinase-9 expression. Sci Rep 2016;6:19720.

15. Liu JH, Li C, Zhang CH, et al. LncRNA-CASC7 enhances corticosteroid sensitivity via inhibiting the PI3K/ AKT signaling pathway by targeting miR-21 in severe asthma. Pulmonology 2020;26:18-26.

16. Narayanankutty A. PI3K/Akt/mTOR Pathway as a Therapeutic Target for Colorectal Cancer: A Review of Preclinical and Clinical Evidence. Curr Drug Targets 2019;20:1217-26.

17. Pal I, Mandal M. PI3K and Akt as molecular targets for cancer therapy: current clinical outcomes. Acta Pharmacol Sin 2012;33:1441-58.

18. Yang G, Lu X, Yuan L. LncRNA: a link between RNA and cancer. Biochim Biophys Acta 2014;1839:1097-109.

19. Schmitt AM, Chang HY. Long Noncoding RNAs in Cancer Pathways. Cancer Cell 2016;29:452-63.

Cite this article as: Hao B, Wen H, Sun Y, Le Z, Zhang Z, Liu M, Hu T. LncRNA-CASC7 inhibits the proliferation and migration of colon cancer by negatively regulating the PI3K/ Akt signaling pathway. J Gastrointest Oncol 2021;12(6):28032813. doi: 10.21037/jgo-21-643
20. Sanchez Calle A, Kawamura Y, Yamamoto Y, et al. Emerging roles of long non-coding RNA in cancer. Cancer Sci 2018;109:2093-100.

21. Liao B, Gao F, Lin F, et al. LncRNA CASC7 inhibits myocardial apoptosis in myocardial ischemia-reperfusion rats by regulating MiR-21 expression. Panminerva Med 2019. [Epub ahead of print]. doi: 10.23736/S00310808.19.03728-5.

22. Liu Y, Pan L, Jiang A, et al. Hydrogen sulfide upregulated lncRNA CasC7 to reduce neuronal cell apoptosis in spinal cord ischemia-reperfusion injury rat. Biomed Pharmacother 2018;98:856-62.

23. Xu YL, Liu Y, Cai RP, et al. Long non-coding RNA CASC7 is associated with the pathogenesis of heart failure via modulating the expression of miR-30c. J Cell Mol Med 2020;24:11500-11.

24. Yuan Z, Li Z. Long noncoding RNA UCA1 facilitates cell proliferation and inhibits apoptosis in retinoblastoma by activating the PI3K/Akt pathway. Transl Cancer Res 2020;9:1012-22.

25. Huang Y, Zhang J, Hou L, et al. LncRNA AK023391 promotes tumorigenesis and invasion of gastric cancer through activation of the PI3K/Akt signaling pathway. J Exp Clin Cancer Res 2017;36:194.

26. He R, Wu JX, Zhang Y, et al. LncRNA LINC00628 overexpression inhibits the growth and invasion through regulating PI3K/Akt signaling pathway in osteosarcoma. Eur Rev Med Pharmacol Sci 2018;22:5857-66.

(English Language Editor: C. Betlzar) 